\title{
Correction to: Bioaccessibility and bioavailability of polyphenols from sour mangosteen (Garcinia xanthochymus) fruit
}

\author{
P. Janhavi ${ }^{1,3}$. Sallaram Sindhoora ${ }^{2,3}$. S. P. Muthukumar ${ }^{1,3}$ (1)
}

Published online: 17 June 2020

(c) Springer Science+Business Media, LLC, part of Springer Nature 2020

\section{Correction to: \\ Journal of Food Measurement and Characterization https://doi.org/10.1007/s11694-020-00488-z}

The original version of the article requires an update to the one of the affiliations of the authors in the author group.

The affiliation 'Academy of Scientific and Innovative Research, CSIR-CFTRI, Mysore, Karnataka 570020, India' has been corrected as 'Academy of Scientific and Innovative Research (AcSIR), Ghaziabad 201 002, India'. Also, the ORCID ID of the corresponding author Dr. S.P. Muthukumar has been corrected.

Publisher's Note Springer Nature remains neutral with regard to jurisdictional claims in published maps and institutional affiliations.

The original article can be found online at https://doi.org/10.1007/ s11694-020-00488-z.

S. P. Muthukumar muthukumar@cftri.res.in

1 Department of Biochemistry, CSIR-CFTRI, Mysore, Karnataka 570020, India

2 Department of Fruit and Vegetable Technology, CSIR-CFTRI, Mysore, Karnataka 570020, India

3 Academy of Scientific and Innovative Research (AcSIR), Ghaziabad 201 002, India 